\title{
30 MELHORES RESUMOS DE TRABALHOS APRESENTADOS NO EVENTO XXI JOCAPE (ONLINE) - JORNADA ODONTOLÓGICA DO CAPE
}

Dias 01, 02 e 03 de dezembro de 2021 


\title{
PESQUISA
}

\section{AVALIAÇÃO DE TORQUE TENO VÍRUS EM SANGUE E SALIVA DE PACIENTES CIRRÓTICOS}

\author{
Ana Clara Falabello DE LUCA*, Gabriella Bueno MARINHO, Natalia da Silva \\ ANDRADE, Paulo Henrique BRAZ DA SILVA, Karem Lopez ORTEGA. \\ FOUSP/CAPE
}

Introdução: Pacientes cirróticos apresentam disfunção imune relacionada ao prejuízo ao sistema reticuloendotelial, quadro potencializado de inflamação sistêmica e latência viral. Torque teno vírus (TTV) pode infectar hepatócitos e estar vinculado com doença hepática criptogênica e cirrose, e ser um possível marcador do estado imunológico. Objetivos: correlacionar a deficiência imune e dados da cirrose com a carga viral de TTV e verificar se a saliva pode ser um biomarcador eficaz. Métodos: Trata-se de um estudo observacional transversal, com análise de dados de prontuários clínicos e quantificação de TTV através da técnica de PCR em tempo real em amostras de sangue e saliva de 85 pacientes cirróticos em fila de transplante. Resultados: As análises estatísticas foram realizadas com nível de significância de $p<0,05$. Foram avaliadas amostras de sangue e saliva e prontuário clínico de 85 pacientes, sendo que 72 preencheram os critérios de inclusão para o estudo. A amostra foi majoritariamente de indivíduos do sexo masculino ( $n=51,70,8 \%$ ), com média de idade de 54,8 anos (DP=10,0) e mediana do índice MELD 15. A etiologia da cirrose foi predominantemente hepatite $C(n=21 ; 31,4 \%)$. Cópias de TTV foram detectadas em 28 amostras de sangue (38,8\%) e 67 amostras de saliva $(93,0 \%)$. $44,4 \%$ dos pacientes possuíam valores de linfócitos indicativos de imunossupressão. Estatisticamente, não houve correlação entre a carga viral de TTV e imunossupressão. Conclusão: A saliva é um biomarcador eficaz na detecção e quantificação de cópias de torque teno vírus por técnica de PCR em tempo real. Uma parcela significativa dos pacientes apresenta alterações indicativas de imunossupressão, entretanto, não foi possível estabelecer uma relação de causaefeito com a carga viral de TTV nessa amostra. Apoio Financeiro: Fundação de Amparo à Pesquisa do Estado de São Paulo (FAPESP). 


\section{ACESSO AO ATENDIMENTO ODONTOLÓGICO POR INDIVÍDUOS COM SÍNDROME DE DOWN QUE FREQUENTAM AS APAES NO ESTADO DE MINAS GERAIS}

Julya Ribeiro CAMPOS*, Guilherme da Rocha CAMPOS, Fernando de Oliveira COSTA, Ana Cristina Borges de OLIVEIRA, Luís Otávio de Miranda COTA UFMG

Introdução:Muitos indivíduos com Síndrome de Down (SD) relatam dificuldade no acesso ao tratamento odontológico. Objetivo: Avaliou-se o acesso ao atendimento odontológico por indivíduos com SD que frequentam as Associações de Pais e Amigos dos Excepcionais (APAEs) de Minas Gerais. Método: A amostra incluiu 184 pais/responsáveis que responderam a um questionário eletrônico relacionado à saúde bucal dos filhos. Resultados: De 181 questionários completos, 148 participantes $(80,4 \%)$ já foram ao dentista para prevenção [n=94 $(51,1 \%)]$, dor/cárie dentária [n=19 (10,3\%)], exodontia [n=20 (10,9\%), erupção dos dentes [n=3 $(1,6 \%)]$ e outros motivos [n=28 (15,2)]. Dos que já foram ao dentista, $120(72,29 \%)$ pais/responsáveis não tiveram dificuldade em conseguir dentista para seus filhos. Sobre dificuldades no acesso, essa questão não se aplicava a maioria [n=90 $(48,9)]$, alguns responderam não ter sido preciso se consultar [n=6 (3,3\%)], para aqueles que encontraram dificuldades os motivos foram encontrar profissional capacitado [ $n=13$ $(7,1 \%)]$, dificuldade financeira/acesso $[n=12(6,5 \%)]$, e medo/insegurança [ $n=8$ $(4,3 \%)]$. As variáveis associadas ao acesso ao atendimento odontológico foram idade $(p<0,001)$ renda $(p=0,032)$, percepção da positiva da saúde bucal $(p=0,043)$, sangramento gengival $(p=0,021)$, dificuldades dos pais/responsáveis na higiene bucal dos filhos $(p=0,003)$, escovação da língua $(p=0,029)$, uso de fio dental $(p=0,0001)$ e frequência de escovação $(p<0,001)$. Permaneceram significativos no modelo multivariado a idade da pessoa com SD [OR=0,174 IC-95\%0,043-0,700 $(p=0,014)$ ] e frequência de escovação [OR=0,033 IC-95\% 0,005-0,228 ( $p=0,001)$ ]. Conclusão: Conclui-se que o acesso ao atendimento odontológico está associado ao aumento da idade da pessoa com SD e aos efeitos protetores dos hábitos de higiene bucal. Ressalta-se a importância do profissional na prevenção das doenças bucais e educação em saúde bucal. 


\section{ODONTALGIA E FATORES ASSOCIADOS EM UMA POPULAÇÃO DE INDIVÍDUOS COM SÍNDROME DE DOWN NO ESTADO DE MINAS GERAIS}

Glayson Pereira VITOR*, Julya Ribeiro CAMPOS, Guilherme da Rocha CAMPOS, Ana Cristina Borges de OLIVEIRA, Fernando de Oliveira COSTA, Luís Otávio de Miranda COTA

FO UFMG

Introdução: Muitos indivíduos com Síndrome de Down (SD) relatam dor dental. Objetivo: o objetivo deste estudo foi avaliar a presença de odontalgia e fatores associados em uma população de indivíduos com SD que frequentam as Associações de Pais e Amigos dos Excepcionais (APAEs) de Minas Gerais. Método: A amostra incluiu 184 pais/responsáveis que responderam a um questionário eletrônico contendo perguntas relacionadas à saúde bucal dos filhos. Resltado: Dos participantes, $48(26,0 \%)$ relataram que seus filhos sentiram dor nos últimos três meses. Odontalgia foi associada à idade elevada $(p=0,007)$, menor frequência de escovação ( $p=0,0001)$, baixa escolaridade dos pais $(p=0,028)$, percepção negativa da saúde bucal $(p<0,001)$, bem-estar geral comprometido $(p=0,0001)$, dificuldade de morder/mastigar alimentos duros $(p=0,002)$, beber ou comer alimentos quentes ou frios $(p<0,001)$, problemas para dormir $(p=0,029)$ e irritação/frustração $(p<0,001)$. Na regressão logística multivariada, odontalgia esteve associada à idade elevada [OR=1,031; IC95\% 1,000-1,061 ( $p=0,048)]$, baixa escolaridade dos pais [OR=6,354; IC95\% 1,512-26,701 ( $p=0,012)$, irritação/frustração da pessoa com SD [OR=12,059; IC95\% 4,083-35,612 ( $p<0,001)]$. Conclusão: Conclui-se que a odontalgia teve uma prevalência considerável, com importantes impactos no bem-estar geral deste grupo. Reforço de práticas de higiene bucal e educação em saúde dos pais são medidas importantes de prevenção das doenças bucais, com potencial para a melhoria da qualidade de vida relacionada a saúde bucal em indivíduos com SD.

(CAAE: 22814919.5.0000.5149) 


\section{AVALIAÇÃO MAXILO-MANDIBULAR DE RATOS TRATADOS COM ÁCIDO ZOLEDRÔNICO}

Liliane Cristine Ferreira de Souza BORGES*, Marco Vinicius CHAUD, Juliana Ferreira de SOUZA, Perla Porto Leite SHITARA.

Universidade de Sorocaba UNISO

Introdução: Os bisfosfonatos (BFs), como inibidores da reabsorção óssea, são utilizados para tratamento da osteoporose desde a década de 60. Este grupo de compostos tem sido utilizado também nos casos de metástase óssea de tumores sólidos, mieloma múltiplo, hipercalcemia e doença de Paget.Objetivo: Diante de diversos casos relatados na literatura de osteonecrose associada aos BFs, o presente trabalho tem por objetivo investigar a associação de necrose óssea à terapia com ácido zoledrônico e procedimento cirúrgico odontológico. Método: O experimento foi realizado in vivo, com 18 animais Rattus norvegicus albinus da linhagem Wistar, machos, admitidos com aproximadamente $120 \mathrm{~g}$. Os animais; foram divididos aleatoriamente em 3 grupos denominados grupos A, B e C. Os animais do grupo A foram submetidos a 3 administrações de ácido zoledrônico $(0,6 \mathrm{mg} / \mathrm{kg})$ e submetidos a exodontia, o grupo $B$ foram submetidos a 3 administrações do ácido zoledrônico e não foram submetidos a exodontia, o grupo $C$ não foi submetido a administração do ácido zoledrônico e foi submetido a exodontia. Alterações alveolares foram investigadas por meio da análise histológica. Resultado: Os animais tratados com ácido zoledrônico e submetidos à exodontia apresentaram osteonecrose $(60 \%)$; os animais submetidos a terapia com ácido zoledrônico apresentaram irritação periorbital $(58,3 \%)$ e pH da urina básico $(91,7 \%)$.Conclusão: A presente pesquisa permitiu concluir que o uso de ácido zoledrônico foi fator de risco para o desenvolvimento de osteonecrose principalmente quando o uso está associado à procedimento cirúrgico odontológico. Pesquisa desenvolvida com apoio da FAPESP. 


\section{AVALIAÇÃO DA HIGIENE ORAL DE PACIENTES COM SONDA ENTERAL}

Lara Teschi BRAVO, Juliane Avansini MARSICANO, Claudia de Oliveira Lima COELHO, Gustavo de Almeida LOGAR

Faculdade de Odontologia de Presidente Prudente, UNOESTE

Introdução: A terapia nutricional fornece ao trato gastrointestinal os nutrientes necessários, sendo que a eleição da via de nutrição dependerá das condições clínicas do paciente. Existem três tipos de sondas, sendo elas: gastromia, nasoentérica e nasogás-trica. No ambiente hospitalar há mais patógenos e, consequentemente, com o passar dos anos, os pacientes ficam mais vulneráveis a outros tipos infecções. Objetivo: Avaliar a higiene oral de pacientes que se alimentam por meio de sonda enteral. Metodologia: Foram avaliados 10 pacientes com uso de dieta enteral e 25 pacientes do grupo controle com dieta via oral. Os pacientes eram dentados e foram submetidos a avaliação do índice higiene oral simplificado (IHOS), índice gengival (IG) e índice de saburra língua (ISL). As variáveis foram tabuladas e submetidas a uma análise exploratória e posteriormente foram aplicados os testes estatísticos Wilcoxon. Resultados: Os pacientes do grupo teste, apresentaram aumento significativo nos IHO-S, IG e ISL em comparação com o grupo controle, onde os resultados do p-value foram, 0,000492; 0,006948; 0,000012, respectivamente. Em relação ao IHO-S, o grupo teste apresentou escore bom $\mathrm{n}=2$ $(20 \%)$, regular $n=5(50 \%)$, deficiente $n=1(10 \%)$ e péssima $n=3(30 \%)$, enquanto no grupo controle o escore bom foi de $n=21(84 \%)$, regular $n=2(8 \%)$, deficiente $n=2$ (8\%) e nenhum paciente apresentou escore péssimo. Conclusão: $A$ incidência de placa e cálculo, inflamação gengival e saburra lingual nos pacientes avaliados foi pior se comparados aos pacientes do grupo controle, por conta disso, é necessário a adoção de estratégias educacionais e a capacitação dos profissionais e/ou cuidadores para melhoria do cuidado e higienização bucal dos pacientes que fazem o uso de sonda enteral. 


\section{OSTEORRADIONECROSE DOS MAXILARES EM PORTADORES DE CÂNCER DE CABEÇA E PESCOÇO - OVERVIEW DE REVISÕES SISTEMÁTICAS}

Gabriella Torres SCHRÖTER*, Renata Maria Mamprin STOPIGLIA, Susana MORIMOTO, Fábio de Abreu ALVES, Maria Stella MOREIRA FOUSP/CAPE

Introdução: A osteorradionecrose (ORN) é considerada um evento tardio e a maior complicação pós radioterapia em pacientes portadores de câncer de cabeça e pescoço. Objetivo: Avaliar a evidência existente dos métodos preventivos e terapêuticos da ORN pós radioterapia e/ou quimioterapia em adultos portadores de câncer de cabeça e pescoço. Métodos: foi realizada uma busca sistemática de revisões sistemáticas que abordassem sobre ORN nas bases de dados eletrônicas MEDLINE/PubMed, Cochrane Central Register of Controlled Trials, Web of Science, Open Gray e manual. Os critérios de inclusão foram: ser revisão sistemática de estudos clínicos, abordar incidência, tratamento ou prevenção da ORN dos maxilares. Os critérios de exclusão foram: comentários, editoriais, estudos duplicados, estudos in vitro. A seleção dos estudos, coleta de dados, avaliação de qualidade metodológica (AMSTAR 2) e de evidência (GRADE) foi conduzida por dois examinadores independentes e calibrados, um terceiro examinador foi consultado em caso de incongruências. Resultados: Dos 1321 artigos identificados, 13 foram considerados elegíveis. Numa visão global a incidência de ORN foi de $6,2 \%$. A mandíbula é o local mais acometido. A exodontia foi apontada como o principal fator causal para o desenvolvimento de ORN. O uso da câmara hiperbárica tem potencial na prevenção da ORN. O tratamento para a ORN com pentoxifilina e tocoferol demonstrou eficácia superior em relação ao uso de antibioticoterapia e câmera hiperbárica. Conclusão: A pentoxifilina e tocoferol apontam ser o tratamento mais promissor. O nível atual de evidência é baixo para as abordagens preventivas e curativas da ORN. 


\section{SANGRAMENTO GENGIVAL RELATADO E FATORES ASSOCIADOS EM UMA AMOSTRA DE INDIVÍDUOS COM SÍNDROME DE DOWN}

Ana Paula de Carvalho da Fonseca CRUZ*, Julya Ribeiro CAMPOS, Fernando de Oliveira COSTA, Ana Cristina Borges de OLIVEIRA, Luís Otávio de Miranda COTA UFMG

Introdução: O sangramento gengival em indivíduos com Síndrome de Down (SD) é um achado importante, podendo estar relacionado com fatores psicossociais e clínicos. Objetivos: Este estudo objetivou avaliar a presença de sangramento gengival relatado pelos pais/responsáveis e fatores associados em indivíduos SD que frequentam as Associações de Pais e Amigos dos Excepcionais (APAEs) de Minas Gerais. Métodos: Este estudo foi aprovado pelo Comitê de Ética em Pesquisa da UFMG (CAAE \#22814919.5.0000.5149). Resultados: A amostra incluiu 184 pais/responsáveis que responderam a um questionário eletrônico contendo perguntas relacionadas à saúde bucal dos filhos e características familiares. De um total de 177 questionários completos, 62 indivíduos (35\%) apresentaram sangramento gengival relatado pelos seus pais/responsáveis. Na análise univariada o sangramento gengival foi associado à idade $(p=0,003)$, halitose $(p=0,001)$, falta do uso de fio dental $(p=0,003)$, nunca ter ido ao dentista $(p=0,028)$, percepção negativa da saúde bucal $(p=0,003)$, comprometimento do bem-estar geral $(p=0,006)$, feridas na boca $(p=0,001)$, irritação/frustração com a saúde bucal $(p<0,001)$ e dor de dente $(p<0,001)$. Na análise multivariada, permaneceram significativas no modelo final: halitose [OR=5,574 - IC95\% 2,313-13,428 ( $p<0,001)]$, uso de fio dental [OR=0,343 - IC95\% 0,164-0,718 (p=0,005)] e irritação/frustração [OR=4,277 IC95\% 1,953-9,367 $(p<0,001)$. Conclusão: Conclui-se que o sangramento gengival teve uma ocorrência considerável nesta população aumentando as chances de comprometimento clínico, psicossocial e comportamental. Práticas de higiene bucal, especialmente o uso de fio dental, devem ser incentivadas como medidas preventivas para o sangramento gengival. 


\section{PERFIL DO PACIENTE E QUALIDADE DO TRATAMENTO ENDODÔNTICO EM INDIVÍDUOS COM DEFICIÊNCIA INTELECTUAL: ESTUDO RETROSPECTIVO}

Marcela Cristina da LUZ* Pontes, Fabiana MESQUITA Barros, Ana Carolina CORAZZA Pedro, Wallena ALBUQUERQUE da Cunha, Marina GALLOTTINI FOUSP/CAPE

Introdução: Indivíduos com deficiência intelectual (DI) apresentam condições de saúde bucal mais precárias em comparação à população em geral. Os fatores relacionados à pobre saúde bucal incluem dificuldade na higienização, limitado acesso à serviços odontológicos e comorbidades. A falta de prevenção e de tratamento precoce da cárie e da doença periodontal, exige por vezes tratamentos mais complexos, como a terapia endodôntica. À percepção dos cirurgiões-dentistas, comportamentais dos pacientes com DI e condições de saúde precária seriam obstáculos na realização do tratamento endodôntico, levando-os a optarem pela exodontia.

Objetivo: Nosso objetivo é avaliar as dificuldades, nível de colaboração e taxa e sucesso de tratamentos endodônticos em pacientes com DI.

Método: Foram coletados dados dos prontuários de 40 pacientes com DI submetidos a terapia endodôntica, no CAPE, entre 2016 e 2021. Coletamos os dados demográficos, doença de base do paciente, grau de DI (leve, moderada ou severa), números de consultas, sucesso imediato do tratamento, intercorrências.

Resultados: Dos 40 pacientes atendidos, 21 eram do sexo masculino (52,5\%), 19 feminino (47,5\%), com idade entre 12 e 62 anos, 19 pacientes (47\%) exibiam nível severo de DI. Dos 52 dentes cujo tratamento endodôntico foi indicado, 38 (73,07\%) foram finalizados . Seis dentes não foram finalizados devido à falta de colaboração do paciente, 4 foram indicados para exodontia, 2 exibiram pulpite reversível, 1 por falta de autorização da mãe, e 1 seguiu em acompanhamento.

Conclusão: A DI severa não foi impeditiva para a realização e sucesso do tratamento endodôntico, na maioria dos casos. 


\section{PREVALÊNCIA DE NEOPLASIAS MALIGNAS ORAIS E MAXILOFACIAIS EM PACIENTES PEDIÁTRICOS - ESTUDO RETROSPECTIVO}

Wallena ALBUQUERQUE da Cunha*, Ana Carolina CORAZZA Pedro, Marcela Da LUZ Pontes, Marina Helena Cury GALLOTTINI

FOUSP/CAPE

Introdução: Neoplasias malignas em crianças e adolescentes são raras. Não obstante, faz se necessário reforçar a importância de levantamentos epidemiológicos de neoplasias na região de cabeça e pescoço para determinar a prevalência e características clínicas-demográficas da população estudada. Objetivo: Avaliar a prevalência de neoplasias malignas orais em crianças e adolescentes por meio de laudos anatomopatológicos emitidos pelo Laboratório de Patologia Oral e Maxilofacial da Faculdade de Odontologia da Universidade de São Paulo (LPOMFOUSP).

Método: Analisou-se retrospectivamente os laudos anatomopatológicos emitidos pelo LPOM, no período entre 1997 e 2021, de pacientes entre 1 e 17 anos de idade. Foram compilados dados demográficos, sítio da lesão, tipo de biópsia, hipótese diagnóstica e diagnóstico final.

Resultados: Durante o período de 1997 a 2021,o LPOM-FOUSP emitiu 101.528 diagnósticos histopatológicos, dos quais $8 \%$ (8.204) foram de crianças e adolescentes, e destes $32(0.39 \%)$ corresponderam a neoplasias malignas. Os tipos mais prevalentes foram os sarcomas (18/32;56.3\%), seguidos por carcinomas $(7 / 32 ; 21.9 \%)$, linfomas $(5 / 32 ; 15.6 \%)$, melanoma $(1 / 32 ; \quad 3.1 \%)$ e ganglioneuroblastoma $(1 / 32 ; 3.1 \%)$. Pacientes do sexo masculino, na faixa etária de 4-11 anos (47\%) foram os mais acometidos e o principal sítio anatômico foi a mandíbula (25\%). Em 40.6\% dos casos (13/32) a hipótese diagnóstica da lesão biopsiada era de lesão de natureza benigna. Conclusões: As neoplasias malignas pediátricas orais e maxilofaciais são raras. Entender as lesões malignas nessa população auxilia os profissionais a reduzir o tempo de diagnóstico e consequentemente melhorar o prognóstico de cura. 


\section{TESTE DE GERAÇÃO DE TROMBINA COMO PREDITOR DE RISCO HEMORRÁGICO EM PACIENTES COM CIRROSE HEPÁTICA: REVISÃO SISTEMÁTICA}

Ana Clélia ROUSSENQ*1 ${ }^{*}$ Vanessa Cristina Corrêa da SILVA ${ }^{1}$, Juliana FRANCO $^{2}$, Karem López ORTEGA ${ }^{1}$, Jefferson TENÓRIO ${ }^{3}$

${ }^{1}$ CAPE- FOUSP

${ }^{2}$ Serviço de Odontologia do Hospital Auxiliar de Suzano - Hospital das Clínicas da Faculdade de Medicina da USP.

${ }^{3}$ UFF

Introdução: Estudos têm demonstrado que os testes convencionais de coagulação como TP/INR e contagem de plaquetas não conseguem predizer o risco de sangramento em indivíduos com cirrose, devido à hemostasia rebalanceada. Testes de geração de trombina (TGT) têm sido apontados como alternativa, por avaliarem os fatores coagulantes e pró-coagulantes.Objetivos: Realizar revisão sistemática da literatura sobre a relação entre o TGT e a avaliação do risco de sangramento em pacientes com cirrose. Metodologia: $O$ trabalho foi inscrito na plataforma Próspero (CRD42012563020) e, seguindo o protocolo PRISMA, foram definidos os termos de busca para serem aplicados nas bases de dados PubMed®, Embase, LILACS, Web of Science, Scopus, Cochrane e Google acadêmico. Estudos que avaliaram TGT para análise do quadro hemostático de pacientes com doenças hepáticas crônicas foram incluídos, sem limite de data de publicação. Revisões sistemáticas, estudos em animais ou em crianças foram excluídos. Resultados: Inicialmente, 163 estudos foram identificados e 20 repetições foram excluídas. Após a análise dos 143 títulos, restaram 34 resumos. Com a leitura completa dos trabalhos, 16 artigos foram incluídos. Não houve inclusão de artigo por referência. 12 estudos apontaram que os TGTs identificaram hipercoagulabilidade. 4 estudos relataram que a hemostasia dos pacientes com cirrose era similar a de pacientes controle. Conclusão: De modo geral, os estudos revelaram que os TGT são confiáveis para avaliação da hemostasia na população analisada, predizendo risco de trombose e hipercoagulabilidade em indivíduos com cirrose, mesmo que valores de PT/INR indicassem o contrário. Os TGT, portanto, parecem promissores para prever o risco de eventos hemorrágicos em indivíduos cirróticos. 


\section{ANÁLISE FRACTAL DO OSSO NEOFORMADO APÓS EXODONTIA EM PACIENTES COM DOENÇAS RENAIS}

Paula Joaquim Bratfisch LINS*, Natália Silva ANDRADE, Rubens CALIENTO, Claudio COSTA, Marina GALLOTTINI

FOUSP/CAPE

Introdução: A insuficiência renal crônica (IRC) causa desordens no metabolismo ósseo levando a alterações bioquímicas e clínicas. O emprego das terapias renais substitutivas, como hemodiálise e transplante renal, não elimina essas desordens. Objetivos: Analisar comparativamente a qualidade do osso neoformado no alvéolo após exodontia em indivíduos transplantados renais (GTR), insuficientes renais crônicos em hemodiálise (GIRC) e sem doença renal (GC), por meio da dimensão fractal (DF) e intensidade de pixels (IP) de radiografias periapicais. Métodos: Avaliamos radiografias periapicais de 17 pacientes do GC, 12 do GTR e 48 do GIRC, obtidas aos 7 e 60 dias após exodontias. A densidade óssea alveolar (DOA) foi determinada pela IP e a complexidade do osso trabecular (COT), pela DF, através do programa ImageJ. Resultados: A diferença da DF entre o dia 7 e o dia 60 foi menor no GTR quando comparado ao GIRC e GC (0,03, 0,09 e 0,12, respectivamente; $p<0,05)$. A diferença da IP entre 7 e 60 dias foi menor no GTR em relação ao GC $(4,55$ e 14,62, respectivamente; $p<0,05)$. No GTR houve correlação moderada inversamente proporcional entre o ganho de DOA e valores de cálcio sérico $(r=-0,667)$.Conclusão: Após exodontia, os pacientes transplantados renais exibiram formação óssea de menor densidade e menor complexidade que os demais participantes. Inferimos que o uso de glicocorticoides e inibidores de calcineurina podem contribuir para a pobre neoformação óssea nestes indivíduos. O valor médio de DOA e de COT dos participantes com insuficiência renal crônica foi estatisticamente semelhante aos valores médios dos pacientes controle. Mas mais estudos devem ser realizados nesse grupo frente à heterogeneidade e presença de doença óssea mineral em alguns deles. 


\title{
EXODONTIA EM PACIENTES COM DIABETES MELITTUS: ESTUDO RETROSPECTIVO
}

\author{
Marina TUMA*, Natália Silva ANDRADE, Marina GALLOTTINI. \\ FOUSP/CAPE
}

Introdução: A literatura científica médica traz evidências que suportam a hipótese de que a hiperglicemia e a diabetes mellitus (DM) aumentam o risco de infecção e atraso na cicatrização após procedimentos cirúrgicos de grande porte. Muitos autores extrapolaram esse conceito para cirurgia menores, como as exodontias. Estudos prospectivos têm sugerido que complicações após exodontias apresentam prevalência semelhante em pessoas com e sem diabetes. Objetivo: Avaliar retrospectivamente a frequência de complicações após exodontias em pacientes com DM tipo 1 e 2. Métodos: Entre 718 prontuários de pacientes com DM, 267 haviam sido submetidos a exodontias. Coletamos dados demográficos, tipo de diabetes, tempo de duração, comorbidades, exodontias realizadas, prescrição de terapia antibiótica profilática e/ou terapêutica e complicações trans e pós operatórias relatadas. Resultados: Dos 267 prontuários, 73 (27,3\%) eram de pacientes com DM tipo 1 e $194(72,7 \%)$ com DM tipo 2. A maioria era do sexo masculino $(139 / 267 ; 52,1 \%)$, com a média da idade de 49,5 anos. No total 794 exodontias foram realizadas. Em 149 (149/794;18,9\%) intervenções os dentistas prescreveram antibiótico. Complicações pós-operatórias foram registradas em 41 (41/794;5,2\%) prontuários, 29 em pacientes com DM tipo 2 (71\%), 12 com DM tipo $1(6,4 \%)$ e em $08(5,4 \%)$ casos haviam sido prescrito antibiótico após a intervenção. Dos 41, 21 não informaram qual complicação, 5 registraram dor, 5 presença de espícula óssea, 2 abcessos, 2 atraso na cicatrização, 3 alveolite, 1 edema, 1 parestesia e 1 trismo. Conclusão: As complicações pós-operatórias não foram frequentes em pacientes com DM. A maioria das complicações aconteceram em pacientes com DM tipo 2. 


\section{AVALIAÇÃO DA SAÚDE BUCAL DE CRIANÇAS INTERNADAS EM UNIDADES DE TERAPIA INTENSIVA PEDIÁTRICA}

Heloisa Carmecide REIS*, Reyna Aguilar QUISPE, Fabiana Francine Ferreira POZO, Brena Manzano RODRIGUES, Paulo Sergio da Silva SANTOS FOB - USP

Introdução: a saúde bucal influencia na condição sistêmica das crianças na UTIP, porém os estudos relativos a uma avaliação padronizada são escassos. Objetivo: avaliar a saúde bucal de crianças internadas na unidade de terapia intensiva pediátrica através de uma graduação visual-quantitativa.

Métodos: Estudo retrospectivo, observacional, através da análise de prontuários eletrônicos de crianças internadas em uma unidade de Terapia intensiva pediátrica (UTIP) geral. Foram incluídas informações de 62 crianças quanto a evolução do atendimento odontológico e graduação da saúde bucal através do bedside oral exam (BOE), tipo de dentição e descrição das lesões bucais. Informações como doença de base, motivo de internação, dias de internação na UTIP, data da primeira avaliação da saúde bucal, uso de dispositivos de suporte respiratório, medicações e exames laboratoriais também foram registrados. Resultados: De 62 crianças internadas na UTIP, 53,2\% eram do sexo feminino e $46,8 \%$ do sexo masculino, com idade média de 3 anos, a maioria com intubação orotraqueal 88,7\%. A saúde bucal foi moderada em $83,9 \%$, boa em $9,7 \%$ e ruim em $6,5 \%$. Não houve associação estatística significativa entre os tipos de dentições e o grau de saúde bucal $(p>0.05)$ ). Porém, crianças com saúde bucal boa ou sem mudanças significativas, corresponderam a crianças edêntulas ou com dentição decídua. Crianças com creatinina elevada, plaquetopenia e neutropenia sempre tiveram algum tipo de alteração da saúde bucal. Conclusão: A maioria das crianças na UTIP tem saúde bucal moderada, algumas destas crianças quando edêntulas ou com dentição decídua têm boa saúde bucal mesmo após a internação. Crianças com níveis elevados de creatinina, plaquetopenia ou neutropenia apresentaram alteração de saúde bucal moderada ou ruim. 


\title{
CASO CLÍNICO
}

\section{ABORDAGEM PERIO-ORTO EM PACIENTE COM HEMOFILIA A GRAVE}

\author{
Bárbara Soldatelli BALLARDIN*, Amanda Rossi CORELHANO, Hudson Balthazar \\ CALVACANTE, Giovana XAVIER, Cassius Carvalho TORRES-PEREIRA \\ Universidade Federal do Paraná
}

Um homem com 32 anos de idade, diagnosticado com Hemofilia A grave na infância, compareceu à consulta odontológica com queixa de estética prejudicada, sangramento gengival intenso e espontâneo, mobilidade dentária, aumento gengival e mau hálito. No exame clínico, foi identificada condição hematológica estável com reposição do fator de coagulação de rotina e relato de tratamento ortodôntico prévio sem acompanhamento posterior. Na avaliação intra-oral, apresentava diastemas e vestibuloversão dos dentes ântero-superiores, hiperplasia gengival inflamatória generalizada, cálculo dentário, sangramento gengival, áreas com secreção purulenta à sondagem e perda óssea horizontal confirmada através de radiografia panorâmica. Inicialmente foi realizada a abordagem periodontal quinzenalmente com raspagens supra e subgengivais, associadas à orientação de higiene bucal, prescrição de bochecho de clorexidina 0,12\%, amoxicilina e metronidazol durante 7 dias. Após a estabilização do quadro periodontal, iniciou-se o tratamento ortodôntico com um método híbrido: uso de aparelho metálico fixo convencional associado a um alinhador removível de acetato com o objetivo de possibilitar a higienização e manutenção periodontal. Foram aplicadas forças leves e biológicas compatíveis com o suporte periodontal reduzido e menor desconforto pela aparatologia fixa. A hiperplasia gengival inflamatória reduziu significativamente e o paciente seguiu em acompanhamento ortodôntico combinado com raspagens periodontais e controle de biofilme bacteriano. A condição periodontal e hematológica não foi impeditiva para a abordagem ortodôntica e o presente relato demonstra a resolutividade do planejamento integrado mesmo em condições de saúde pouco frequentemente tratadas pelo ortodontista. 


\section{LESÕES ORAIS ASSOCIADAS A DOENÇA DO ENXERTO CONTRA O HOSPEDEIRO AGUDA COM DIAGNÓSTICO HISTOPATOLÓGICO}

Gabriela Silveira de ARAUJO*, Maria Julia PAGLIARONE, Renato Luiz Guerino CUNHA, Thiago de Carvalho REIS, Leandro Dorigan de MACEDO.

FRMP-USP/ HCRP-USP

A doença do enxerto contra o hospedeiro aguda (DECHa) é uma das principais complicações do transplante alogênico de células tronco hematopoiéticas (TCTH-alo). Os fatores de risco incluem a incompatibilidade do sistema de antígenos leucocitários humanos (HLA), sexo, idade entre doador e receptor, intensidade do regime de condicionamento, profilaxia ineficaz e fonte periférica de células-tronco. $O$ acometimento da cavidade oral é pouco descrito e muitas vezes confundido com a mucosite oral (MO). O objetivo deste trabalho foi descrever o acometimento da mucosa oral por DECHa em paciente submetido ao TCTH-alo. Paciente do sexo masculino, 57 anos, com diagnóstico prévio de Leucemia mieloblástica, risco intermediário, submetido a um TCTH-alo, doador aparentado do sexo masculino, HLA idêntico (10/10), isogrupo $A B O$, fonte medula óssea, condicionamento FLUMEL 140 e profilaxia para DECH com ciclosporina e metotrexato. Apresentou MO grau IV (OMS) no D+9, resolvida no $D+15$. No $D+19$ paciente apresentou enxertia neutrofílica e lesões em pele, que foram biopsiadas com diagnóstico de DECHa grau IV. Iniciado tratamento padrão com corticoide, com resposta clínica parcial. No D+37 relatou ardência em mucosa oral e no D+41 evoluiu com ulcerações extensas em mucosa jugal, ventre lingual e lábio inferior. As lesões orais foram submetidas a biópsias que confirmaram padrão histológico compatível com DECHa grau III. Após ajuste do tratamento para DECHa refratária (anti-timuglobulina e células mesenquimais), o paciente evoluiu com resolução completa das lesões orais. No entanto, faleceu no D+69 após recaída da doença de base. Este relato de caso apresenta a importância da avaliação histológica para $\mathrm{DECHa}$ de boca, em especial nos processos inflamatórios tardios para o desenvolvimento de MO. 


\section{IMPLICAÇÕES ODONTOLÓGICAS EM PACIENTE COM TROMBASTENIA DE GLANZMANN}

Ítalo Oliveira BARBOSA*, Ana Cristina Correa da SILVA, Raphaella de Oliveira Pinto CALDAS, Jéssika Brito da COSTA, Juliana Bertoldi FRANCO.

Divisão de Odontologia - Instituto Central - Hospital das Clínicas da Faculdade de Medicina da USP

A Trombastenia de Glanzmann (TG) é uma doença hemorrágica autossômica recessiva rara caracterizada pela ausência de agregação plaquetária sendo considerada uma plaquetopatia, com elevado risco de sangramento em procedimentos odontológicos cruentos, em que alguns autores utilizam a infusão de hemoderivados na prevenção de eventos hemorrágicos. $O$ objetivo desse trabalho é relatar um caso de um paciente com TG, do sexo feminino, 42 anos, em acompanhamento odontológico no Hospital das Clínicas da FMUSP com queixa de sangramento oral com frequência. Ao exame clínico intra-oral, foi observado cálculo supra e subgengival, bem como a presença de sangramento gengival espontâneo e de coágulos nas margens gengivais dos dentes anteriores inferiores. Considerando as condições clínicas odontológicas da paciente, realizou-se a remoção dos coágulos na margem gengival e raspagem supra e subgengival com auxílio de curetas manuais, com o objetivo de eliminar os fatores locais que poderiam exacerbar o sangramento, sendo adotado manobra hemostática local com curativo compressivo à base de ácido tranexâmico e recomendações pós-operatória. Foi prescrito bochecho com clorexidina $0,12 \%, 2 x /$ dia e orientações de higiene oral. Na consulta de retorno, foi observado melhora do quadro de sangramento e da saúde periodontal. Pacientes portadores de discrasia sanguínea, como a TG, apresentam elevado risco de sangramento durante e após procedimentos odontológicos, com necessidade de planejamento que envolvem meios hemostáticos locais. Esse tipo de abordagem, por sua vez, tem possibilitado a realização de procedimentos cirúrgicos mais seguros para os pacientes com discrasia sanguínea sem a necessidade de transfusão de hemoderivados. 


\section{MIÍASE EM CAVIDADE ORAL EM PACIENTE COM ADNPM: PROTOCOLO ASSISTENCIAL E IMPLICAÇÕES BIOÉTICAS}

Ana Luiza Barboza VIANNA*, Ana Cristina Correa da SILVA, Jéssika Brito da COSTA, Raphaella de Oliveira Pinto CALDAS, Juliana Bertoldi FRANCO.

Divisão de Odontologia - Instituto Central - Hospital das Clínicas da Faculdade de Medicina da USP

As infestações parasitárias em cavidade oral por miíase são acontecimentos incomuns e estão associadas a presença de bolsas periodontais, halitose, ausência de selamento labial e higiene oral precária, sendo observada em pacientes neurológicos ou acamados. O objetivo do trabalho é relatar o caso da paciente, sexo feminino, 30 anos, com atraso de desenvolvimento neuropiscomotor (ADNPM) que compareceu em caráter de urgência ao serviço de odontologia acompanhada pela mãe com história de desaparecimento por 7 dias em região próxima ao domicílio, apresentando escabiose e míiase em cavidade oral. Ao exame clínico foi observado a presença de larvas em região de lábio inferior e rebordo alveolar dos dentes anteriores superior e inferior. Em uma abordagem inicial ambulatorial foi realizada remoção das larvas visíveis e desbridamento sob anestesia local, com estabilização protetora, e prescrição de dose única de ivermectina $6 \mathrm{mg}$ e antibioticoterapia. Na consulta de reavaliação paciente compareceu ao ambulatório agitada, agressiva e pouco colaborativa, impedindo o exame clínico, sendo encaminhada para procedimento em centro cirúrgico sob anestesia geral. Foi realizado acesso profundo em lábio inferior para remoção das larvas, exodontias de dentes com mobilidade e tratamento periodontal. Paciente permaneceu internada por 24 horas após o procedimento, sendo solicitado alta hospitalar pela mãe da paciente, não sendo realizado seguimento do caso. Pessoas vulneráveis estão sujeitos a autonomia do responsável legal, em que o objetivo principal é a tomada de decisão para a proteção do indivíduo, mas que nesse caso apresentou desfecho negativo, não possibilitando a assistência adequada a paciente e seguimento até a resolução completa do caso. 


\section{EXODONTIA EM PACIENTE PORTADOR DE ANEMIA APLÁSTICA GRAVE: ABORDAGEM ODONTOLÓGICA EM EQUIPE MULTIDISCIPLINAR}

Camila Cristina Panisello FERREIRA*, Christyan Moretti PEREIRA, Ana Luiza Barbosa VIANNA, Maria Paula Siqueira de Melo PERES, Juliana Bertoldi FRANCO Hospital das Clínicas da Faculdade de Medicina da Universidade de São Paulo.

A anemia aplástica (AA) é uma doença rara que pode apresentar pancitopenia moderada a severa devido a hipocelularidade acentuada na medula óssea. O diagnóstico consiste na detecção de pancitopenia no hemograma e confirmação com a biópsia de medula óssea, sendo o tratamento definido pela idade do paciente, gravidade da doença, presença de morbidades e disponibilidade de um doador aparentado compatível para transplante de medula óssea. O objetivo do trabalho é relatar o caso de um paciente do sexo masculino, 57 anos, portador de AA Grave com histórico de múltiplas transfusões de hemocomponentes, doença de Chagas e osteoporose, além do uso de marcapasso. Foi encaminhado pela Hematologia, devido a dor intensa em região anterior de maxila e sangramento gengival generalizado, apresentando exames hematológicos pré-operatórios com $9,7 \mathrm{mil} / \mathrm{mm}^{3}$ de plaquetas e $0,0 \mathrm{mil} / \mathrm{mm}^{3}$ neutrófilos. Ao exame físico intra oral notou-se dentição parcial superior e inferior, condição de higiene oral insatisfatória e comprometimento pulpar em dente 23, com indicação de exodontia. Após discussão entre as equipes, optou-se por transfusão de concentrado de plaquetas no pré-operatório devido à plaquetopenia grave e realizou-se profilaxia antibiótica para endocardite. No transoperatório foi utilizado curativo local com ácido tranexâmico macerado como medida hemostática. Paciente retornou sem queixas de sangramento, e não foi observado hematomas ou petéquias na área da exodontia. $O$ caso evidencia a importância do tratamento em equipe multidisciplinar de pacientes com patologias que necessitam de intervenção hospitalar, como a transfusão de hemocomponentes, além do conhecimento e habilidade do cirurgião-dentista para a realização do procedimento para a redução das intercorrências trans e pós-operatórias. 


\section{HIPERPLASIA GENGIVAL MEDICAMENTOSA EM PACIENTE COM SÍNDROME DE ALPERS-HUTTENLOCHER}

Marcus Vinícius BUENO*, Mariana Oliveira BESSELER, Milton HANASHIRO, Maria Paula Siqueira de Melo PERES, Juliana Bertoldi FRANCO

Serviço de Odontologia do Hospital Auxiliar de Suzano - Hospital das Clínicas da Faculdade de Medicina da USP.

A síndrome de Alpers-Huttenlocher é uma doença mitocondrial autossômica recessiva rara causada por uma mutação no gene POLG1, que leva à redução da funcionalidade da polimerase gama, componente chave da replicação e reparo do DNA mitocondrial. Alterações na atividade enzimática resultam em níveis reduzidos e/ou deleções dentro do DNA mitocondrial com manifestações fenotípicas e sintomas como convulsões, degeneração do fígado e atraso do desenvolvimento neuropsicomotor. Esta patologia é uma doença rapidamente progressiva que se apresenta no início da vida e apresenta alta taxa de mortalidade. Hiperplasia gengival induzida por drogas é um efeito colateral de imunossupressores, bloqueadores de canais de cálcio e anticonvulsivantes que causam alterações nos fibroblastos gengivais que culminam em dificuldade de higiene bucal, danos estéticos e dificuldade de alimentação. O objetivo do trabalho é relatar o caso de uma paciente do sexo feminino, 5 anos, portadora da síndrome de Alpers-Huttenlocher, transplantada de fígado aos 2 anos de idade, em dependência de ventilação mecânica, em uso de imunossupressores, benzodiazepínicos, anticonvulsivantes e corticoides, que ao exame clínico intra-oral foi observado exuberante hiperplasia gengival medicamentosa em maxila com exteriorização da cavidade oral associada ao atraso da erupção dos dentes decíduos, dano estético e respiração bucal. O uso de anticonvulsivantes e imunossupressores ocasiona modificações aos tecidos gengivais que são muitas vezes desconhecidos pela equipe multidisciplinar. Devido ao quadro geral da paciente faz-se necessário o planejamento para a realização de gengivoplastia em centro cirúrgico para controle da hiperplasia gengival, diminuição do risco de infecção oral e melhora da qualidade de vida da paciente. 


\section{A IMPORTÂNCIA DA ODONTOLOGIA NA RECUPERAÇÃO DA AUTOESTIMA EM PESSOA VIVENDO COM HIVIAIDS: RELATO DE CASO}

Alexandre Cândido da SILVA*, Isabela Cambuí MEIRA, Luana Pavan VIANELLO, Élcio Magdalena GIOVANI, Levy Anderson César ALVES

USCS e Programa IST/AIDS da Prefeitura Municipal de São Paulo

A temática que envolve a pessoa vivendo com HIVIAIDS ainda representa um desafio mundial, alicerçado pela epidemiologia de novos casos de infecção pelo vírus, sendo que ações em nível multiprofissional são importantes e que envolvem também a Odontologia. Neste contexto, a saúde bucal participa, muitas vezes, como ator principal na recuperação do paciente, não somente pela perspectiva técnica, mas também social, constituindo o processo motivacional peça importante na recuperação da autoestima durante as ações clínicas. Relato de Caso: Paciente, JR, 47 anos, portador de HIV, em quadro de AIDS, com queixa de ferida em boca, encaminhado para a avaliação na Clínica de Odontologia, sem uso de Terapia Antirretroviral (TAR). Ao exame clínico, observa-se quadro de Queilite Angular em comissura labial lado esquerdo e lesão por PPR mal adaptada em assoalho bucal. Paciente diagnosticado também com quadro de Lipodistrofia Facial e perda significativa de Dimensão Vertical de Oclusão. Durante a consulta foi valorizada a questão da reinserção em sociedade, melhoria da qualidade de vida e a importância do autocuidado. Foi realizado adequação bucal, confecção de Prótese Total Superior e Parcial Inferior e valorizado a cada consulta a importância das drogas antirretrovirais para controle do vírus. Após 01 (um) ano de acompanhamento, houve melhora significativa do quadro do paciente, com ganho de autoestima, reinserção social e entendimento da importância da TAR. Logo, depreende-se que os profissionais envolvidos no atendimento de pacientes com necessidades especiais dentro da esfera das moléstias infecciosas, têm papel importante na recuperação da autoestima do mesmo, por meio de uma assistência de caráter humanizado aliado ao conhecimento técnico e científico. 


\section{ATENDIMENTO DOMICILIAR EM CRIANÇA COM TRISSOMIA DO CROMOSSOMO 9 - TIPO MOSAICO}

Cintia Aparecida Alves LEMOS, Renata O GUARÉ

UNICSUL - Universidade Cruzeiro do Sul

A Trissomia do Cromossomo 9 do tipo mosaico (T9M) é um distúrbio multissistêmico raro com fenótipo clínico amplo com grande variabilidade individual, risco aumentado de problemas pré-natais e perinatais, e associação com idades parentais avançadas. Os achados principais são dismorfismos craniofaciais, malformações de múltiplos órgãos e atraso de DNPM. O objetivo é relatar as características gerais e bucais, bem como o tratamento odontológico efetuado em criança com T9M, em âmbito domiciliar. Criança de 2 anos e 6 meses, sexo feminino, assistida por home care, com visita odontológica domiciliar durante a pandemia, devido a relato de inquietação, segundo a mãe. A paciente faz uso de sonda nasogástrica e recém introdução de alimentos líquidos via GTT, com a presença de válvula antirefluxo. Ao exame clínico observou-se gengivite generalizada, presença de área avermelhada em região de palato e hematoma de erupção no 54. Foi realizada orientação de higiene com dentifrício fluoretado para mãe e cuidadoras, com individualização de técnicas: escova unitufo para molares, uso de fio dental com haste, raspador de língua, e abridor de boca com palitos. Para o tratamento da candidíase foi utilizado o antifúngico tópico (solução VASA), por 3 semanas, com remissão da lesão. O atendimento odontológico domiciliar em T9M requer uma visão humanizada, qualificando o cuidado na primeira infância e melhorando sua qualidade de vida. 


\section{VARIANTES EM LTBP3 (LATENT TRANSFORMING GROWTH FACTOR-BETA BINDING PROTEIN) CAUSA AMELOGÊNESE IMPERFEITA HIPOPLÁSICA}

Kêmelly Karolliny Moreira RESENDE*, Paulo Márcio YAMAGUTI, Juliana Forte Mazzeu de ARAÚJO, Ana Carolina ACEVEDO

UnB

A amelogênese imperfeita (Al) é uma condição genética caracterizada por alterações quantitativas e/ou qualitativas do esmalte dentário, pode ser classificada em Al não sindrômica e sindrômica. Recentemente com o avanço dos conhecimentos moleculares, variantes no gene LTBP3 foram relatadas em anomalias dentárias e baixa estatura. Estudos mencionam seu envolvimento no desenvolvimento craniofacial e de tecidos mineralizados. $O$ objetivo deste estudo foi realizar o diagnóstico clínico e molecular de uma família com $\mathrm{Al}$ autossômica recessiva (AIAR). Paciente do sexo feminino,23 anos de idade, foi encaminhada à Unidade de Saúde Bucal no Hospital Universitário de Brasília aos 8 anos de idade com queixa de alteração no esmalte dentário. No exame clínico revelou-se Al hipoplásica, calcificação intrapulpares, erupção ectópica e baixa estatura. Não foi identificado alterações esqueléticas similares à braquiolmia. Exames complementares: Após assinatura do TCLE foi coletado sangue venoso, extraído DNA pelo método salting out é realizado sequenciamento de nova geração de exoma completo. $\mathrm{Na}$ análise molecular identificou-se no caso índice variantes em heterozigose composta no gene LTBP3, são elas LTBP3:C.3214C>T e LTBP3: c.85_105del:p.(29_35del). Os resultados obtidos nesse estudo sugerem que as variantes no gene LTBP3 identificadas estão associadas a AIAR e baixa estatura. Previamente, há relato de um caso em família brasileira com fenótipo semelhante, no entanto com braquiolmia, mas a análise molecular não foi realizada. Para nosso conhecimento esse estudo é o primeiro relato de paciente brasileiro com AIAR e baixa estatura com variante no gene LTBP3.

Apoio financeiro: Cofecub/CAPES, Decanato de Pesquisa e Inovação/Universidade de Brasília. 


\section{EXODONTIAS EM PACIENTE COM FIBRODISPLASIA OSSIFICANTE PROGRESSIVA: RELATO DE CASO}

Matheus CORREAA-SILVA, Ana Luiza Barboza VIANNA, Ana Cristina Correa da SILVA, Raphaella de Oliveira Pinto CALDAS, Luiz Alberto Valente SOARES-JUNIOR.

Divisão de Odontologia - Instituto Central - Hospital das Clínicas da Faculdade de Medicina da USP

A fibrodisplasia ossificante progressiva (FOP) é uma desordem genética rara, com dominância autossômica. A incidência de FOP é extremamente rara, afetando 1:2.000.000 pessoas, sem predileção por sexo ou etnia. A ossificação heterotópica $(\mathrm{OH})$ normalmente se inicia na primeira década de vida. O objetivo deste trabalho é relatar um caso de exodontias em paciente portadora de FOP. Paciente do sexo feminino, 21 anos, com diagnóstico de FOP desde os 4 anos de idade. Compareceu ao ambulatório de odontologia do ICHCFMUSP, após longo período sem acompanhamento odontológico com queixa de fratura dentária. Ao exame paciente apresentava assimetria facial e desvio postural em coluna cervical, torácica e lombar devido à formação de $\mathrm{OH}$. Ao exame intra oral apresentava abertura bucal de $23 \mathrm{~mm}$, dentes 36 e 46 com mobilidade grau III e dente 37 com cárie extensa. Como plano de tratamento foi proposto a exodontia do 36,37 e 46 . Os procedimentos foram realizados em 2 tempos cirúrgicos com intervalo de 2 semanas. A profilaxia com prednisona ( $2 \mathrm{mg} / \mathrm{kg} / \mathrm{dia})$ foi prescrita iniciando 24 horas antes do procedimento e mantida por mais 5 dias. As exodontias foram realizadas sob anestesia local utilizando a técnica intraligamentar e o procedimento foi realizado de forma mais atraumática possível. No acompanhamento pós-operatório, a paciente relatou dor e sinais de infecção local na região abordada. Após terapia antibiótica por 7 dias paciente apresentou remissão de sintomatologia, porém foi possível observar início de formação de $\mathrm{OH}$ limitada ao local onde houve a infecção. No entanto, não houve alteração de abertura bucal após o procedimento. Sendo assim, o presente relato demonstra que o tratamento odontológico do paciente com FOP merece uma série de cuidados específicos. 


\section{CANDIDÍASE PERSISTENTE EM OROFARÍNGE PELO USO CRÔNICO DE BUDESONIDA.}

Juli Emily Costa GUIMARÃES*, Ana Cristina Corrêa da SILVA, Ana Luiza Barboza VIANNA, Jéssika Brito da COSTA, Juliana Bertoldi FRANCO.

Divisão de Odontologia - Instituto Central - Hospital das Clínicas da Faculdade de Medicina da USP

O uso de corticoides inalatórios facilita infecções oportunistas, como a candidíase, devido a imunossupressão e a hipossalivação ocasionados. A candidíase se manifesta como placas brancas removíveis à raspagem ou na forma eritematosa acometendo a mucosa oral, orofaringe e trato gastrointestinal. O objetivo desse trabalho é relatar um caso de um paciente, do sexo masculino, 40 anos, portador de sarcoidose pulmonar, silicose e anemia ferropriva em uso crônico de budesonida (4X/dia), prednisona e sabultamol, apresentando ao exame clínico oral candidíase pseudomembranosa em orofarínge recorrente e persistente, sendo observado clinicamente placas brancas removíveis em região de palato mole, envolvendo a úvula. Paciente referiu ser acompanhado pelo pneumologista que o tratou com fluconazol e nistatina. No entanto, sem melhora do quadro, sendo o paciente encaminhado para avaliação odontológica. Em uma abordagem odontológica inicial foi realizada citologia esfoliativa com resultado positivo para candidíase. Em um segundo momento, realizou-se aplicação de terapia fotodinâmica (aPDT) em placas de orofaringe, e foi solicitado reavaliação do uso crônico da budesonida (4x/dia) ao pneumologista, pois este medicamento poderia estar associado ao quadro de candidíase recorrente devido a imunossupressão local e hipossalivação. Após 3 sessões de aPDT e redução da dose de budesonida observou-se melhora importante em relação ao quadro de infecção oportunista. Pacientes que fazem uso de corticoides inalatórios podem apresentam risco aumentado para infecções oportunistas em cavidade oral, e cabe ao cirurgião-dentista a realização de uma boa anamnese, exame clínico, tratamento e boa comunicação com a equipe multidisciplinar para a obtenção dos melhores resultados. 


\section{FASE FINAL DA VIDA: ALÍVIO DA DOR TOTAL ATRAVÉS DE REABILITAÇÃO PROTÉTICA}

Lis Mayra Silva SANTOS*, Ricardo Tavares de CARVALHO, Sumatra Melo da Costa Pereira JALES,

Ana Carolina Porrio de ANDRADE, Zenon Ribeiro Castelo BRANCO.

Hospital das Clínicas da Faculdade de Medicina da Universidade de São Paulo

Cuidado Paliativo (CP) é definido como a assistência promovida por uma equipe multidisciplinar, que objetiva a melhoria da qualidade de vida do paciente e seus familiares, diante de uma doença que ameace a continuidade da vida, por meio da prevenção e alívio da dor e do sofrimento em todas as suas dimensões. A falta de dentes pode impactar em todas as dimensões do cuidado pois compromete a função mastigatória além da estética, provoca constrangimento e angústia pela redução da autoestima.

Mulher, 45 anos, portadora de cirrose hepática, com limitação de suporte terapêutico devido à impossibilidade de transplante hepático internada em uma enfermaria de CP em processo ativo de morte. Na avaliação odontológica, a paciente com tristeza expressou "dor na alma" e intenso sofrimento após remoção das próteses fixas unitárias dos dentes \#13 e \#22 por mobilidade e risco de aspiração. Paciente pouco contactuante, sonolenta, dieta via oral, pele facial ictérica, lábios ressecados e com crostas. Ao exame da cavidade oral, dentada parcial, com crostas, hipossalivação grave. Apesar da proximidade da morte, optou-se pela cimentação das próteses fixas e contenção com resina composta, além de hidratação bucal e labial. A biografia e os valores do indivíduo devem ser considerados em abordagem de CP, considerando não apenas a sua doença, mas as suas dimensões psicológicas, sociais e espirituais. O alívio da dor total através da reabilitação protética nos últimos dias de vida, impactou positivamente na qualidade de vida e contribuiu para um processo de morte digno e com menos sofrimento. 


\section{TRATAMENTO ORTOCIRÚRGICO DE PACIENTE COM DISPLASIA CLEIDOCRANIANA: RELATO DE CASO}

Heloisa GONSALVES*, Gabriella Bueno MARINHO, Patrícia Verónica Aulestia VIERA, José Benedito Dias LEMOS

\section{FOUSP/CAPE}

A displasia cleidocraniana é uma malformação genética, sem predileção por sexo e ampla expressividade clínica. Os traços mais característicos são a hipoplasia das clavículas, a ossificação deficiente da fontanela anterior, presença de dentes supranumerários, erupção dentária tardia, hipoplasia do terço médio da face, testa volumosa e hipertelorismo. Os múltiplos dentes supranumerários podem se desenvolver devido a reativação da lâmina dentária no momento da formação da coroa completa dos dentes permanentes. Este estudo relata o caso de uma paciente com displasia cleidocraniana, sexo feminino, 18 anos, que procurou a Especialização de Cirurgia e Traumatologia Bucomaxilofacial da Fundação Faculdade de Odontologia conveniada à FOUSP para avaliação dos elementos supranumerários e de necessidade de cirurgia ortognática para compensação de alterações ósseas. No exame clínico notou-se bossa frontal proeminente, perfil facial dolicocefálico, prognatismo mandibular, mordida aberta, assimetria facial, presença de dentes decíduos em boca e alterações no terço médio da face, como o hipertelorismo. Durante o exame radiográfico notou-se a presença de múltiplos dentes supranumerários inclusos e impacção de parte dos dentes permanentes. Foram realizados procedimentos cirúrgicos para a extração de elementos supranumerários e planejamento em conjunto com a ortodontia para tracionamentos, compensação e possível preparo para cirurgia ortognática. Este caso demonstra a importância do planejamento multidisciplinar no sucesso do tratamento de alterações maxilofaciais que impactam diretamente na qualidade de vida de pacientes acometidos pela displasia cleidocraniana. 


\section{RELATO DE CASO DE SÍNDROME DE MOHR}

Vanessa Cristina Corrêa da SILVA*, Ana Clélia ROUSSENQ, Nathália BELLIS, Juliana LOYOLA, Karem López ORTEGA

FOUSP/CAPE

Síndromes orofaciodigitais são transtornos raros do desenvolvimento com incidência de 1:1.000.000 de nativivos. Há presença de malformações em boca, face e dedos. São de herança autossômica recessiva e 13 tipos clínicos já foram relatados na literatura. O tipo 2 é conhecido como Síndrome de Mohr (OMIN 304700) e suas manifestações clínicas mais características são fenda labiopalatina, hamartomas na língua e alterações em dedos e face. Paciente do sexo feminino, 37 anos, procurou atendimento odontológico no Centro de Atendimento a Pacientes Especiais (CAPE) com queixa de maloclusão. No exame físico extra-oral foram detectados baixa estatura, hipoplasia em terço médio da face, hipertelorismo, fissura palpebral antimongolóide, hipoplasia do terço médio da face, malformação do pavilhão auditivo externo, retração da linha de implantação capilar frontal elevada, ponte nasal alargada e hipertricose na região de filtro labial. Nas mãos, foram identificados dedos curtos e achatados, clinodactilia dos dedos anelares e má-formação com maior alargamento na porção falange distal dos dedos indicadores. O exame intra-oral revelou fibromatose gengival, mal posicionamento dentário, dentes semi-erupcionados, hipodontia na arcada inferior e overbite.Tratamentos dentários são importantes não só em termos estéticos, mas também funcionais para pacientes com esse tipo de síndrome. A oclusão alterada e o desenvolvimento comprometido dos ossos maxilares podem acarretar prejuízos na mastigação e na articulação temporomandibular. A multidisciplinaridade no atendimento é fundamental para o adequado manejo e melhora na qualidade de vida de indivíduos portadores desse transtorno. 


\section{MANEJO ODONTOLÓGICO EM PACIENTE COM DISTROFIA MUSCULAR DE DUCHENNE EM USO PROLONGADO DE BISFOSFONATO ORAL:RELATO DE CASO}

Christiane Caminiti CHIARADIA*, Marcela Cristina da LUZ Pontes, Marco SQUADRANS, Karem López ORTEGA, Fabiana MARTINS.

FOUSP/CAPE

A Distrofia Muscular de Duchenne (DMD) é definida como um distúrbio neuromuscular degenerativo ligado ao cromossomo $X$, onde mutações genéticas levam a modificação na produção da distrofina, proteína envolvida na manutenção da integridade muscular. Tem predominância pelo sexo masculino, com incidência de 1:3.500 nascimentos. O uso de corticosteroides tem início após o diagnóstico, para retardar o processo degenerativo da doença, porém a longo prazo, há chance para o desenvolvimento de osteoporose. Então bisfosfonatos orais são indicados para evitar fraturas patológicas. Paciente do sexo masculino, leucoderma, 27 anos, em uso de corticosteroides e bisfosfonato oral há 20 anos. Apresentava dor espontânea contínua na região dos dentes anteroinferiores e exsudato em face vestibular do dente 41 , outras alterações observadas eram higiene oral regular e mordida em topo. Radiograficamente apresentava imagem radiolúcida difusa na região. $O$ planejamento clínico consistiu na instalação de uma placa acrílica rígida no arco superior, antibioticoterapia, tratamento periodontal e terapia fotodinâmica antimicrobiana. Após dois anos de seguimento clínico, o paciente relatou melhora na dor, e o não uso da placa acrílica por alguns meses, o que pode ter favorecido a persistência da lesão periapical, com exsudato. Foi realizado tratamento endodôntico de todos os dentes inferiores anteriores, com resolução do quadro infeccioso. Pessoas com DMD em uso prolongado de corticosteroides e bisfosfonatos exibem risco aumentado para o desenvolvimento de osteonecrose associada ao uso de medicamentos, por este motivo, é fundamental que se faça o controle e eliminação de focos infecciosos. 


\section{CARCINOMA EPIDERMÓIDE EM PACIENTE TRANSPLANTADO: RELATO DE CASO CLÍNICO}

Elidiane Elias RIBEIRO*, Ana Gabriela BAUSEN, Cristina de Carvalho Guedes ABREU, Marcele Farias Silva MONTEIRO, Karin Sá FERNANDES

FOUSP/CAPE

O carcinoma epidermóide é a neoplasia maligna mais comum em boca, caracterizado pela presença de células pleomórficas hipercromáticas, exibindo mitoses atípicas e adentrando tecido conjuntivo. Acomete em geral homens com idade acima de 50 anos, com maior prevalência em indivíduos com história de alto consumo de tabaco e álcool. Paciente do sexo masculino, 63 anos, tabagista, hipertenso, foi submetido à um transplante de fígado em 2015 devido à cirrose alcóolica, e compareceu recentemente ao CAPE-FOUSP para consulta odontológica de rotina. O paciente fazia uso de micofenolato de sódio, tacrolimo, AAS, amlodipina, sinvastatina, cilostazol e AD-TIL. Ao exame intraoral foi observado lesão ulcerada, granulomatosa e eritroplásica em região retromolar do lado esquerdo que se estendia para orofaringe, com aproximadamente $2,5 \mathrm{~cm}$. Foi realizada biópsia incisional e procedeu-se a análise histopatológica. Individualmente as células neoplásicas exibiam hipercromatismo nuclear, alteração da relação núcleo/citoplasma e figuras de mitose atípicas. De acordo com os aspectos clínicos e histopatológicos, o diagnóstico foi de carcinoma epidermóide. O carcinoma epidermóide oral é uma neoplasia maligna de etiologia multifatorial, relacionada a diversos fatores intrínsecos (nutricionais, imunossupressão) e extrínsecos (tabaco, álcool). O paciente era fumante, e fazia uso de tacrolimo, sendo que este medicamento realiza a ativação da via RAS (gene humano que pode sofrer mutação) e induz o crescimento tumoral. Diversos estudos mostram a maior incidência de neoplasias malignas após transplante de fígado em pacientes em uso de imunossupressores, mas há poucos relatos de carcinoma epidermóide oral, como observado neste caso clínico, sendo uma alerta para o cirurgião dentista. 


\section{ABORDAGEM CIRÚRGICA DA HIPERPLASIA GENGIVAL EM PACIENTE HEBIÁTRICO COM SÍNDROME FIBROMATOSE HIALINA: RELATO DE CASO.}

Catielma Nascimento SANTOS*, Consuelo Brandão Coube de CARVALHO, Danielle Santos QUINDÓS, Luana CAMPOS, Fabiana MARTINS e Martins de Oliveira FOUSP/CAPE

A Síndrome Fibromatose Hialina (SFH) caracteriza-se por um crescimento anormal do tecido fibroso hialino. É uma síndrome rara, autossômica recessiva, em que ocorre mutação no gene ANTXR2. De interesse odontológico, a SFH causa hiperplasia gengival, que sem intervenção cirúrgica dificulta a alimentação e a higiene oral favorecendo infecções. A cirurgia para remoção dos nódulos pode ser feita com bisturi frio, eletrocautério ou laser de alta potência. Assim, o objetivo desse trabalho foi descrever um relato de experiência sobre a cirurgia de remoção dos nódulos hiperplásicos em paciente hebiátrico utilizando duas técnicas: o eletrocautério e o laser de alta potência. Paciente de sexo feminino, 13 anos, com diagnóstico clínico e genético de SFH leve, com vários nódulos na gengiva recobrindo todos os dentes. A paciente estava sem acompanhamento odontológico desde o início da pandemia da COVID-19, o que agravou seu quadro clínico. Foi proposta, como opção de tratamento, a remoção cirúrgica dos nódulos gengivais por sessão. Para isso, foi utilizado o eletrocautério e o laser de alta potência em cirurgias realizadas por hemiarcada. Após a realização da cirurgia com ambas as técnicas, a paciente foi questionada sobre qual o pós-operatório havia sido mais confortável. Segundo a mesma, a cirurgia com o laser de alta potência era menos dolorosa e a cicatrização mais rápida. Em relação à opinião clínica dos profissionais que realizaram ambas as técnicas, o laser de alta potência conseguia remover mais tecido fibroso hialino em menor tempo que o eletrocautério bem como, o processo cicatricial reparador era mais rápido. Apesar de ser um relato de experiência de um único caso, podemos sugerir que o laser de alta potência teve um melhor desempenho clínico em relação ao eletrocautério. 